\title{
Carbamazepine Shows Plasma and Tissue Pharmacokinetic Interactions with Ajuga bracteosa Extract in Rats
}

\section{(๑)( $\odot \Theta$}

\author{
Authors

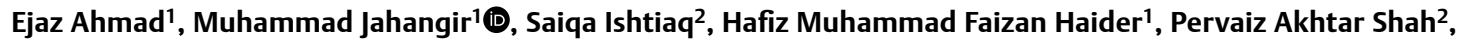 \\ Nadeem Irfan Bukhari²
}

\section{Affiliations}

1 Department of Chemistry, Government College University Lahore, Pakistan

2 Punjab University College of Pharmacy, University of Punjab, Lahore, Pakistan

\section{Key words}

Ajuga bracteosa (family Lamiaceae), bioavailability, carbamazepine, herb-drug pharmacokinetic interactions, HPLC analysis

received 17.08 .2020

received 03.11 .2020

accepted 25.01.2021

\section{Bibliography}

Planta Med Int Open 2021; 8: e10-e18

DOI 10.1055/a-1375-6570

ISSN 2509-9264

(C) 2021. The Author(s).

This is an open access article published by Thieme under the terms of the Creative Commons Attribution-NonDerivative-NonCommercial-License, permitting copying and reproduction so long as the original work is given appropriate credit. Contents may not be used for commercial purposes, or adapted, remixed, transformed or built upon. (https://creativecommons. org/licenses/by-nc-nd/4.0/)

Georg Thieme Verlag KG, Rüdigerstraße 14,

70469 Stuttgart, Germany

\section{Correspondence}

Ejaz Ahmad

Department of Chemistry

GC University

54000 Lahore

Pakistan

Tel.: + 92-333-4626788

ejaz_ravian@yahoo.com

\section{ABSTRACT}

Carbamazepine (CBZ) is the first-line anticonvulsant drug with a narrow therapeutic index (NTI) and is a substrate for CYP3A4 and MRP-2. Ajuga bracteosa (AB), family Lamiaceae is widely used to treat epilepsy, gastric diseases, and protects against liver damage in folk. It contains bioactive metabolites, which are powerful inhibitors of CYP3A4, CYP3A5, CYP19, CYP2C19 enzymes and P-gp transporter. Concomitant use of NTI drugs with herbs, like $A B$ increase the chances of herb-drug interactions (HDIs). This study was aimed to analyze the Ajuga bracteosa crude extract ( $A B C E$ ) and to investigate its effect on the pharmacokinetics of $C B Z$ in rats. In the pre-treatment study, rats received $A B C E(1000 \mathrm{mg} / \mathrm{kg})$ orally for 14 days, followed by a single dose of CBZ $(80 \mathrm{mg} / \mathrm{kg})$ on the $15^{\text {th }}$ day. In the coadministration study, single doses of $A B C E$ and $C B Z$ were administered concomitantly in one session. All the doses were administered in $0.5 \%$ carboxymethylcellulose (CMC) as a vehicle. HPLC analysis showed that extract contained $1.3 \mathrm{mg} / \mathrm{g}$ ursolic acid, $2.1 \mathrm{mg} / \mathrm{g}$ sitosterol and $2.9 \mathrm{mg} / \mathrm{g}$ stigmasterol. Non-compartmental pharmacokinetic analysis showed an increase in $C_{\max }, A U C_{0-\infty}$, MRT, and $t_{1 / 2}$ with a decrease in $t_{\max }, V_{d}$ and $\mathrm{Cl}$ of $\mathrm{CBZ}$ in both, pre-treated and co-administered groups vs controls. An increase in CBZ concentration in liver tissue of both pre-treated as well as co-administered animals was observed as compared to control. The above results suggested possible HDIs between $A B$ and CBZ thus, may warrant $C B Z$ dose adjustment in epileptic patients with simultaneous administration of $A B$ or its products.

$\begin{array}{ll}\text { ABBREVIATIONS } \\ \text { AB } & \text { Ajuga bracteosa } \\ \text { ABCE } & \text { Ajuga bracteosa crude extract } \\ \text { ABC } & \text { ATP-binding cassette } \\ \text { CMC } & \text { carboxymethylcellulose } \\ \text { CBZ } & \text { carbamazepine } \\ \text { CYP } & \text { cytochrome } \\ \text { H\&E } & \text { hematoxylin-eosin } \\ \text { MDR1 } & \text { multidrug resistance protein 1 } \\ \text { MRP-2 } & \text { multidrug resistance protein } 2 \\ \text { P-gP } & \text { P-glycoprotein } \\ \text { HDIs } & \text { herb-drug interactions } \\ \text { NTI } & \text { narrow therapeutic index drug } \\ \text { ROS } & \text { reactive oxygen species }\end{array}$




\section{Introduction}

Approximately 45.9 million people, worldwide suffer from epilepsy [1]. In Pakistan, every 10 out of 1000 people are suffering from epilepsy [2]. The anti-epileptic drugs are not effective in all patients, and $30 \%$ of patients still suffer from seizures, despite using anti-epileptics [3]. While $30-40 \%$ of epileptic patients develop resistance against anticonvulsants on their long-term use [4]. Almost $5.1 \%$ of epileptic patients choose herbal remedies as alternative treatments to synthetic anti-epileptic drugs [5]. Generation of the reactive oxygen species (ROS) in the brain is one of the leading causes of epilepsy, associated with seizures. Natural anti-oxidants prevent the generation of ROS, thus widely used in the treatment of epilepsy [6].

CBZ, a carboxamide derivative ( $\triangleright$ Fig. $\mathbf{1}$ ) is a first-line anticonvulsant allopathic drug with NTI. It is usually prescribed for the treatment of epilepsy, neuropathic pain, bipolar disease, and trigeminal neuralgia [7, 8]. After oral administration, it is absorbed slowly and metabolized mainly in the liver. It has been shown to regulate intestinal multidrug resistance protein 1-P-glycoprotein (MDR1-P-gP) and MRP-2, both belong to the ATP-binding cassette $(A B C)$ efflux transporters and may affect the drug disposition $[9,10]$. CBZ is a powerful inducer of the cytochrome P450 enzyme system and is more prone to interact with herbal remedies when used simultaneously. CBZ, being a substrate of CYP3A4 metabolizes to 10-11 epoxide CBZ which on the accumulation in the body, can lead to toxic effects. CYP2C8 and CYP1A2 also play a vital role in the metabolism of CBZ. Epileptic patients using CBZ for a long time may suffer from gastric discomfort, drug-induced hepatitis and liver damage leading to abnormalities in hepatic biomarkers [11].

Ajuga bracteosa wall ex. Benth (Lamiaceae), locally named as Ratti booti, Neelkanthi or Khurbanti is a perennial herbaceous plant, found in the mountainous regions of Pakistan. The plant is widely used by epileptic patients in folk [12], as the crude extract, as well as fractions of the plant, possess the anticonvulsant action [13]. It also has promising anti-oxidant as well as hepato-protective potentials $[14,15]$. The plant contains 20 -hydroxyecdysone and iridoid glycosides which are potent inhibitors of MDR1-P-gp [16, 17].

Unlike traditional medical treatment, many people now believe in self-care and alternative therapies. Herbal medicine manufacturers do not need to prove their quality and safety and most of these products are unlicensed [18]. The concurrent use of herbs and drugs raises the risk of interactions, which often are overlooked due to the lack of evidence. Well into the case of NTI drugs, the out-

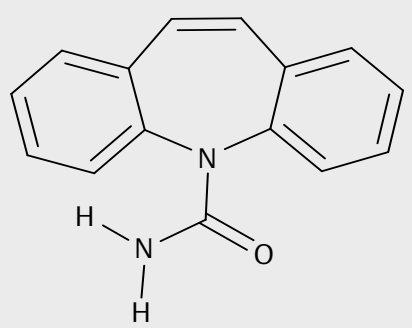

Fig. 1 Chemical structure of CBZ. comes of interactions may be more severe as a result of small changes in their plasma concentrations [19]. It is worth noting that only less than half of the patients pass on information on the use of herbal remedies to their doctors. In addition, health practitioners often do not normally try to probe the usage of herbal preparations $[20,21]$. Anticonvulsant medications, as a therapeutic class have greater chances of interacting with other medicines, food, and herbs. With the widespread use of herbal medicines in patients with epilepsy, the likelihood of their exposure to antiepileptic drugs increases and is currently being realized [22].

Given that the people commonly use $A B$ to treat multiple comorbidities as well as the fact that $C B Z$ is the first-line anticonvulsant medication, patients using $A B$ and $C B Z$ would possibly be discovered simultaneously for treating epilepsy, other diseases, or for any of its above-stated biological activities. Due to the extensive use and the presence of powerful CYP450 inhibitory constituents in $A B$, the interest in this plant is justifiable to explore its effect on the bioavailability of $C B Z$. Moreover, there were no reports on the $A B-C B Z$ interactions, which further triggered this study to evaluate the possible HDIs. Bearing in mind all the above-mentioned reasons, the present study was aimed to analyze the $A B C E$, both qualitatively and quantitatively by using liquid chromatography, as well as to evaluate its pre-treatment and co-administration effect on the pharmacokinetics of CBZ in rats.

\section{Results and Discussion}

To date, the pharmacokinetic HDIs for CBZ, have been studied with polygonum cuspidatum, a resveratrol rich nutraceutical, ferulic acid, sophora flavescens and traditional beverages, including tamarind, mango, sugarcane, and red bull [23-26]. HDls occur primarily during the process of absorption, distribution, metabolism, and clearance of drugs. They may also have an association with a time-dependent induction and inhibition of MDR1-P-gp and/or MRP-2-mediated efflux activity and/or CYPs. MDR1-P-gP is commonly distributed in the intestinal epithelial cells, liver and brain, while MRP-2 is distributed in the apical membranes of, duodenum, jejunum, hepatocytes, brain and kidneys of rats [10, 27-30]. The inhibition of drug metabolism and transporters is an immediate process occurring in $24-48 \mathrm{~h}$ post-dosing while the induction is a slower process happening in 7-10 days. CBZ is simultaneously a substrate for MDR1-Pg-p, MRP-2 and CYP iso-enzymes. The induction or inhibition of MDR1-P-gP and MRP-2 alters the drug bioavailability. Over-expression of MRP-2 causes refractoriness in epileptic patients, which is also believed to be associated with the development of resistance of CBZ and other anti-epileptics [31, 32]. Hypothetically, the dual substrate drugs for CYPs and MDR1-P-gp have higher interaction potential with herbal remedies [19]. AB used to treat arthritis, hypertension, infections, malaria, diabetes and epilepsy, possesses many medicinally important bioactive constituents, which have made it a dual substrate for CYPs and efflux transporters. Patients taking antiepileptic drugs may prefer to use herbal remedies for other comorbidities because they believe that allopathic drugs have a higher risk of side effects. However, herbalists, medical professionals as well as patients are unaware of the HDIs. The majority of the reported HDI studies have been carried out in-vitro using higher doses of therapeutic agents than the clin- 
ically prescribed doses [33]. The appraisal of the interactions between phytomedicines and synthetic pharmacotherapeutic drugs are necessary to carry out in animals before their clinical trials in humans. The issue of HDIs has generated substantial concern in the case of NTI drugs. In line with the above, the present research work assessed the interaction between $A B C E$ and $C B Z$ in rats.

In the current study, the qualitative and quantitative liquid chromatographic analysis revealed that plant extract contained $1.3 \mathrm{mg} / \mathrm{g}$ ursolic acid, $2.9 \mathrm{mg} / \mathrm{g}$ stigmasterol, $2.1 \mathrm{mg} / \mathrm{g}$ and sitosterol. Ursolic acid potently inhibits CYP2C19 iso-enzyme and plays an important role in HDls by altering the pharmacokinetics of the co-administered drugs [34, 35], stigmasterol powerfully inhibits MDR1-P-gp and CYP3A4, CYP3A5, and CYP19 [36, 37] and the sitosterol inhibits CYP3A4 and CYP2D6 [38]. The CYP3A4, CYP2C8, and CYP1A2 play vital role in CBZ metabolism [25, 39, 40]. Pharmacokinetics data indicate the significant effect of strong inhibitors of CYP isoenzymes in plant extracts on the pharmacokinetics of the drug. The presence of the quantified phytochemicals in the $A B$ plant extract might have a significant role in alteration of pharmacokinetics of CBZ, when co-administered.

- Figure 2 shows the mean plasma concentration-time profiles of $C B Z$ in animals pre-treated with $A B C E$ for 14 days and CBZ administration on $15^{\text {th }}$ day. Results of the pre-treatment study revealed a $42.4 \%$ increase in $C_{\max }, 101.4 \%$ in $A U C_{0-\infty}$ and $42.7 \%$ in MRT, while a decrease in $t_{\max }$ by $25.7 \%$ and $V_{d}$ by $29.33 \%$ for CBZ, in the pre-treated group, as compared to the control group-I. The Ke and $\mathrm{Cl}$ were also decreased, respectively by 27.2 and $51.50 \%$ while $t_{1 / 2}$ shown a $47.4 \%$ increase for CBZ in the pre-treated group ( $\triangleright$ Table 1). All the above parameters in the pre-treated group were statistically different $(p<0.05)$ from that of the control group. A significant difference $(p<0.01)$ in CBZ concentrations was revealed at all the time points in the pre-treated group as compared to the control group-I. The pre-treatment study was conducted to observe the time-dependent inhibition/induction effect of $A B C E$ on the pharmacokinetics of CBZ in line with a previous study design [41]. Pre-treatment also mimics a situation where the $A B C E$ utilized for some time, is followed by the use of the CBZ or other dual substrate drugs. Comparison of the reported values with those of the present study ( $\triangleright$ Tables $\mathbf{1}$ and $\mathbf{2}$ ), shows closeness in $t_{\text {max }}$, ke, and
MRT, slightly lesser for $C_{\text {max }}$, AUC and $C l$ while higher for $V_{d}$ (tremendously) and $\mathrm{t}_{1 / 2}$.

- Figure 3 shows the mean plasma concentration-time profiles of CBZ in animals of co-administered study, where control and experimental groups received, respectively the vehicle and plant extract with CBZ simultaneously in one session. The CBZ concentrations were consistently higher, in the co-administered group at the all-time points compared to the control group-III, but only significantly higher $(p<0.05)$ at $3 \mathrm{~h}$. In the co-administered study, the $C_{\max }$, and $\mathrm{AUC}_{0-\infty}$ of $\mathrm{CBZ}$ were increased in the co-administered group by $8.0 \%$ and $61.1 \%$, respectively without a change in $t_{\max }$ as compared to the control group-III ( $\vee$ Table 2 ). The $\mathrm{V}_{\mathrm{d}}$ was reduced by $7.2 \%$, Ke, and $\mathrm{Cl}$ were reduced by $10.0 \%$ and $22.40 \%$, respectively, while an increase in $\mathrm{t}_{1 / 2}$ by $34.7 \%$ was noted in the co-administered group compared to control. Nevertheless, no significant difference was noted in the pharmacokinetic parameters of the

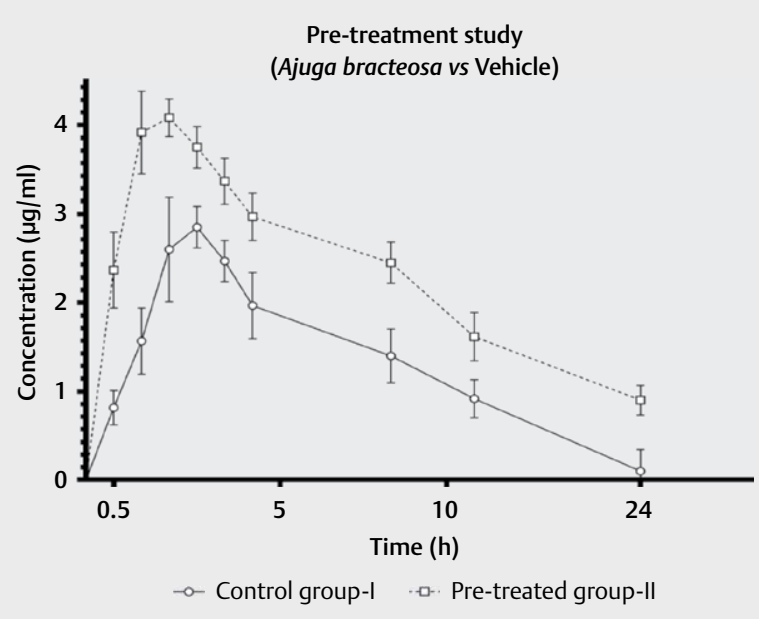

- Fig. 2 Time-dependent mean plasma concentration of CBZ for $24 \mathrm{~h}$ in animals treated orally with $A B C E(1000 \mathrm{mg} / \mathrm{kg})$ or vehicle ( $0.5 \%$ aqueous solution of $C M C)$ for 14 days followed by a single dose of CBZ $(80 \mathrm{mg} / \mathrm{kg})$ on $15^{\text {th }}$ day. Values are represented as mean with $\pm \operatorname{SEM}(n=6)$.

- Table 1 Comparison of pharmacokinetic parameters for control and pre-treated group. Values are expressed as \pm S.E.M ( $\mathrm{n}=6$ ).

\begin{tabular}{|c|c|c|c|c|}
\hline Parameter & Unit & Control group-I & Experimental (Pre-treated) & Trend (\%) \\
\hline$t_{\max }$ & $\mathrm{H}$ & $1.75 \pm 0.12$ & $1.30 \pm 0.12^{*}$ & $\downarrow 25.7$ \\
\hline $\mathrm{C}_{\max }$ & $\mu \mathrm{g} / \mathrm{mL}$ & $3.02 \pm 0.10$ & $4.30 \pm 0.20^{* *}$ & $\uparrow 42.4$ \\
\hline $\mathrm{AUC}_{0-\mathrm{t}}$ & $\mu \mathrm{g} . \mathrm{h} / \mathrm{mL}$ & $21.10 \pm 2.24$ & $46.32 \pm 1.02 * *$ & $\uparrow 119.5$ \\
\hline $\mathrm{AUC}_{0-\infty}$ & $\mu \mathrm{g} \cdot \mathrm{h} / \mathrm{mL}$ & $30.50 \pm 3.04$ & $61.44 \pm 3.76^{* *}$ & $\uparrow 101.4$ \\
\hline MRT & $\mathrm{H}$ & $11.63 \pm 1.27$ & $16.60 \pm 1.93^{*}$ & $\uparrow 42.7$ \\
\hline$V_{d}$ & $\mathrm{~L}$ & $7.40 \pm 1.40$ & $5.23 \pm 1.50 *$ & $\downarrow 29.3$ \\
\hline Ke & $1 / \mathrm{h}$ & $0.11 \pm 0.01$ & $0.08 \pm 0.01$ & $\downarrow 27.2$ \\
\hline$t 1 / 2$ & $\mathrm{H}$ & $7.80 \pm 0.90$ & $11.50 \pm 1.45^{*}$ & $\uparrow 47.4$ \\
\hline $\mathrm{Cl}$ & litre/h & $0.68 \pm 0.30$ & $0.33 \pm 0.10 * *$ & $\downarrow 51.5$ \\
\hline
\end{tabular}

Estimation of pharmacokinetic parameters by non-compartmental analysis for CBZ in plasma of animals orally pre-treated with $\mathrm{ABCE}$ ( $1000 \mathrm{mg} / \mathrm{kg}$ ) or vehicle $(0.5 \%$ aqueous solution of $C M C)$ for 14 days followed by a single dose of CBZ $(80 \mathrm{mg} / \mathrm{kg})$ on $15^{\text {th }}$ day $(\mathrm{n}=6)$. ${ }^{*}$ indicates $\mathrm{p}<0.05$ and $* *$ indicates $\mathrm{p}<0.01$. 
- Table 2 Comparison of pharmacokinetic parameters for control and co-administered group. Values are expressed as \pm S.E.M ( $n=6)$.

\begin{tabular}{|l|l|l|l|c|}
\hline Parameter & Unit & Control group-III & $\begin{array}{l}\text { Experimental (co-admin- } \\
\text { istered) }\end{array}$ & Trend (\%) \\
\hline $\mathrm{t}_{\max }$ & $\mathrm{H}$ & $1.42 \pm 0.20$ & $1.40 \pm 0.10$ & Negligible \\
\hline $\mathrm{C}_{\max }$ & $\mu \mathrm{g} / \mathrm{mL}$ & $3.52 \pm 0.25$ & $3.8 \pm 0.14$ & $\uparrow 8.0$ \\
\hline $\mathrm{AUC} \mathrm{C}_{0-\mathrm{t}}$ & $\mu \mathrm{g} \cdot \mathrm{h} / \mathrm{mL}$ & $20.54 \pm 3.04$ & $33.1 \pm 4.30$ & $\uparrow 61.1$ \\
\hline $\mathrm{AUC} \mathrm{C}_{0-\infty}$ & $\mu \mathrm{g} \cdot \mathrm{h} / \mathrm{mL}$ & $30.5 \pm 2.14$ & $42.2 \pm 4.97$ & $\uparrow 38.4$ \\
\hline $\mathrm{MRT}$ & $\mathrm{H}$ & $9.50 \pm 0.33$ & $12.5 \pm 1.47$ & $\uparrow 31.6$ \\
\hline $\mathrm{V}_{\mathrm{d}}$ & $\mathrm{L}$ & $6.14 \pm 0.80$ & $5.70 \pm 1.28$ & $\downarrow 7.2$ \\
\hline $\mathrm{Ke}$ & $1 / \mathrm{h}$ & $0.10 \pm 0.03$ & $0.09 \pm 0.01$ & $\downarrow 10.0$ \\
\hline $\mathrm{t} 1 / 2$ & $\mathrm{H}$ & $6.40 \pm 0.30$ & $8.62 \pm 1.13$ & $\uparrow 34.7$ \\
\hline $\mathrm{Cl}$ & litre/h & $0.67 \pm 0.20$ & $0.52 \pm 0.30$ & $\downarrow 22.4$ \\
\hline
\end{tabular}

Estimation of pharmacokinetic parameters by non-compartmental analysis for CBZ in rats after oral co-administration of single dose ABCE (1000 mg/ $\mathrm{kg}$ ) or vehicle ( $0.5 \%$ aqueous solution of CMC) with CBZ $(80 \mathrm{mg} / \mathrm{kg})(\mathrm{n}=6)$.

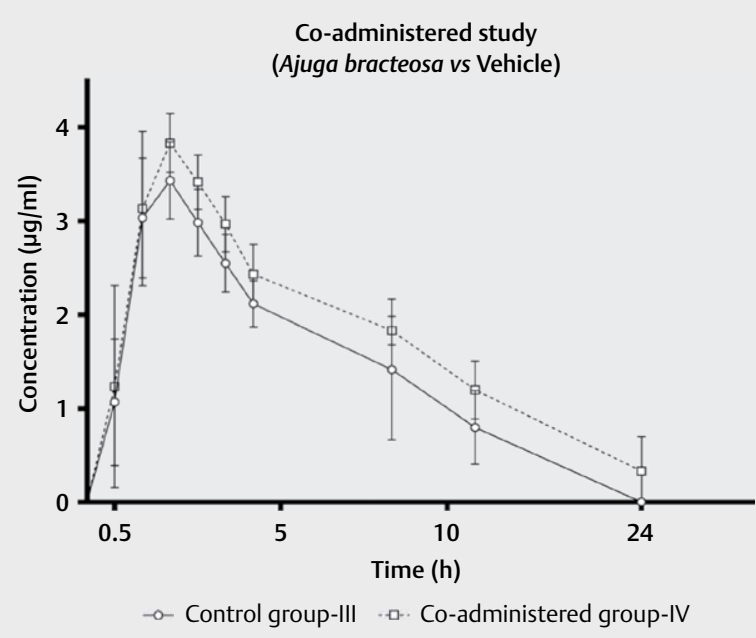

- Fig. 3 Mean $( \pm S E M, n=6)$ concentration profile of $C B Z$ in plasma obtained over a time of $24 \mathrm{~h}$ from rats co-administered with single oral dose of $A B C E(1000 \mathrm{mg} / \mathrm{kg})$ or vehicle $(0.5 \%$ aqueous solution of $\mathrm{CMC})$ and $\mathrm{CBZ}(80 \mathrm{mg} / \mathrm{kg})$.

control group-III and experimental group IV of the co-administration study.

In pre-treated group-II, as compared to co-administered groupIV, the CBZ plasma levels were significantly higher $(\mathrm{P}<0.05)$ at 0.5 , 2.0, 3.0, 4.0, 8.0, 12.0, 24.0 h, being highly significant $(\mathrm{p}<0.01)$ at $2.0,3.0$ and $8.0 \mathrm{~h}$ ( $\triangleright$ Fig. 4). Notable difference $(p<0.01)$ was observed for $\mathrm{AUC}_{0-\infty}$ and $\mathrm{Cl}$ between animals of pre-treated and coadministered groups. The alteration in absorption, metabolism, distribution and elimination rate of the drug was with greater magnitude in pre-treated group-II as compared to co-administered group-IV.

CBZ, being the potent inducer of CYP3A4, CYP2C9 and CYP1A2 [11], shows more metabolism when administered alone leading to a lower drug concentration. A raised $C B Z$ absorption $\left(C_{\max }\right.$ and $A U C_{0-\infty}$ and MRT) in extract-treated groups were observed which could be ascribed to a strong competitive inhibition of the metabolizing isoenzymes by the powerful inhibitors contained in the

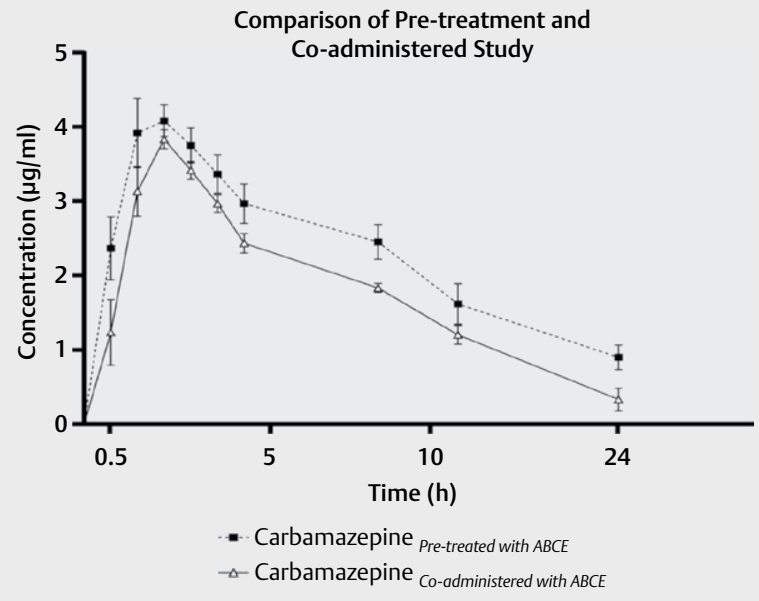

Fig. 4 Comparison of pre-treatment and co-administered study. Values are represented as mean with $\pm \operatorname{SEM}(n=6)$.

$A B C E[17,34-37]$. A reduced Ke as well as prolonged $t_{1 / 2}$ was supported by a lower metabolism and subsequent decrease in plasma drug concentrations in both experimental groups. An increase in MRT indicated a long-term persistence of CBZ in the body in the experimental groups. A higher magnitude of enzyme inhibition by $A B C E$ was observed in pre-treatment as compared to the co-administration, which showed a time-dependent inhibitory effect of the plant extract. CBZ is a polar drug, has high capacity for plasma protein binding and thereby, demonstrates $V_{d}$ of $14.32 \mathrm{~mL} / \mathrm{kg}$ [24] which is equivalent to $3.58 \mathrm{~mL}$. Though a reduction in $V_{d}$ in the group-II and group-IV were noted as compared to group-I and III, which in all cases tremendously exceeded the total physiological volumes of tissues, and extra- and intracellular compartments, i. e., about $400 \mathrm{~mL}[42,43]$.

The raised $C_{\max }$ and $A U C$ values in both extract-treated groups might be attributed to the rapid drug absorption, due to the masking of intestinal MDR1-P-gp and MRP-2 in the presence of ABCE. Considering the above in view, it could be implied that the ABCEled masking of intestinal MDR1-P-gp and MRP-2 and inhibitory ef- 
fect of $A B C E$ on CBZ metabolism outweighs the CBZ's inductive effect, besides the other reasons for the elevated CBZ absorption. Because the basic drugs undergo ionization in the acidic medium for absorption [44], thus being a basic drug, CBZ was expected to be ionized in the rat stomach, $\mathrm{pH} 3.2-3.9$, which in presence of a more basic ABCE, pH 5.90 caused more CBZ's fraction available for absorption in the stomach. A higher drug absorption continued in the duodenum, jejunum and small intestine where the MDR1-P-gP and MRP-2 were also masked by the ABCE in both extract-treated groups. Furthermore, the $A B C E$ probably increased the absorption rate of $C B Z$, indicated by a briefer $t_{\max }$ value.

An increase in $C_{\max }$ and $A U C_{0-\infty}$ is the marker of higher systemic exposure (bioavailability) of a drug to provide a therapeutic effect. A rise in $C_{\max }$ is also likely to be clinically important as it is expected to change the efficacy of drugs [45]. AUC is affected by absorption, metabolism, physicochemical factors, CYP450 isoenzymes, and interaction with herbs, food, and drugs [46-50]. An increased drug bioavailability and systemic exposure could result in the enhanced anti-epileptic effect in the presence of ABCE. However, increased systemic exposure to CBZ may induce hepatic injury and gastrointestinal side effects on long-term use with increased risk of drug toxicity in the body, being a drug with NTI [51].

In the present study, declined Ke as well as increased $t_{1 / 2}$, indicated lesser metabolism and late decline of drug concentration in the blood in pre-treated animals in the presence of ABCE compared to the co-administration group. The $\mathrm{V}_{\mathrm{d}}$ and $\mathrm{Cl}$ were decreased in pre-treated group-II as compared to co-administered group-IV. $\mathrm{V}_{\mathrm{d}}$ refers to the distribution of the drug between plasma and the rest of the body. Lower $V_{d}$ and Ke indicates higher drug plasma concentration as the above decreased the value of $\mathrm{Cl}$. The extent of distribution and elimination of the drug is governed by $\mathrm{Cl}$, which tends to become lower when AUC is higher for a given dose, as it is the ratio of the drug dose to the AUC [41]. Based on the above findings, a lower dose of CBZ might be required to accomplish a given plasma concentration. Decreased $V_{d}$ and $C l$ were likely to be due to increased bioavailability of the drug in pre-treated group-II as compared to co-administered group-IV.

The effect of pre-treatment and co-administration with $A B C E$ on the tissue distribution of CBZ is shown in > Fig. 5a, b, respectively. The higher CBZ concentration in the brain, liver and kidney were found in extract-treated groups as compared to the respective controls. A notably higher concentration of CBZ in liver tissue was observed at $24 \mathrm{~h}$ post-dosing as compared to other tissues.

- Table 3 shows the tissue/plasma ratio for the liver of control group-I and III equal to 0.2 , which is in-line with the previously reported value of 0.16 [52]. The prominently increased drug concentration in the liver of both extract-treated groups is evidence of MDR1-P-gP and MRP-2 inhibition in the liver by ABCE, which by suppressing the drug exit from the liver, interplayed with the enzyme inhibition in the organ caused more tissue localized drug. Likewise, the markedly higher concentration of CBZ in the brain of extracttreated groups demonstrated masking of the role of MDR1-P-gP and MRP-2-mediated activity in the brain tissue. More tissue distribution of CBZ in both extract treatedgroups as compared to respective controls, did not correspond with the decreased $V_{d}$ in the presence of $A B C E$, which implied that the relatively lesser drug was moved to tissues than the blood, though this still exceeded all the physiological volumes. Nevertheless, the above results also advocated the possible promising role of ABCE towards enhancement of the anti-epileptic effect of the drug. On the other hand, the
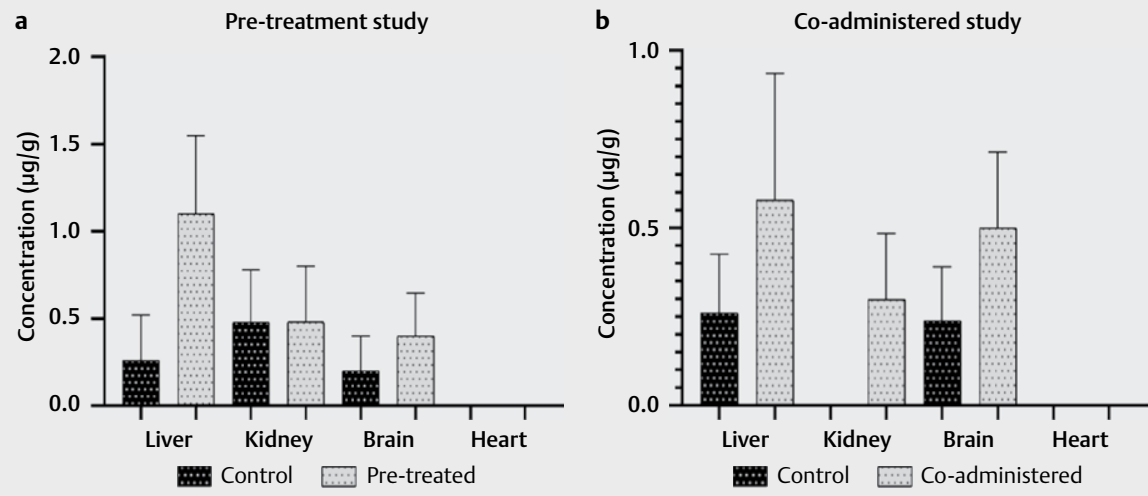

Fig. 5 Mean concentration ( \pm SEM, $n=6)$ of $C B Z$ in liver, kidneys, heart and brain of animals a after orally treated with $A B C E(1000 \mathrm{mg} / \mathrm{kg})$ or vehicle ( $0.5 \%$ aqueous solution of CMC) for 14 days followed by a single dose of CBZ $(80 \mathrm{mg} / \mathrm{kg})$ on $15^{\text {th }}$ day. $\mathbf{b}$ After orally co-administered with ABCE $(1000 \mathrm{mg} / \mathrm{kg})$ or vehicle $(0.5 \%$ aqueous solution of $\mathrm{CMC})$ and $\mathrm{CBZ}(80 \mathrm{mg} / \mathrm{kg})$.

- Table 3 Tissue concentration of CBZ in pre-treatment and co-administered studies at $24 \mathrm{~h}$ post-dosing. Values are expressed in terms of the mean of $\mathrm{n}=6$.

\begin{tabular}{|l|l|l|l|l|l|}
\hline Treatment groups & Plasma & Liver & Heart & Kidney & Brain \\
\hline Control group-I & 0.6 & $0.2 / 0.6$ & $0 / 0.6$ & $0.5 / 0.6$ & $0.2 / 0.6$ \\
\hline Experimental (pre-treated) group & 0.9 & $1.1 / 0.9$ & $0 / 0.9$ & $0.5 / 0.9$ & $0.4 / 0.9$ \\
\hline Control group-III & 0.0 & $0.2 / 0$ & $0 / 0$ & $0 / 0$ & $0.2 / 0$ \\
\hline Experimental (co-administered) group & 0.5 & $0.6 / 0.5$ & $0 / 0.5$ & $0.3 / 0.5$ & $0.5 / 0.5$ \\
\hline
\end{tabular}


minor increase of $C B Z$ concentration in kidney tissue implied an insignificant role of ABCE on MDR1-P-gP and MRP-2-mediated activity in the kidney. The above findings of this HDI study supported that the extract masked both MDR1-P-gp and MRP-2 or anyone of the above more remarkably in the brain tissue compared to that in the kidneys. Moreover, the prominently higher concentration of drug in the liver tissues of extract-treated animals suggested that the repeated and simultaneous treatment with ABCE could contribute to more drug accumulation in the liver, leading to hepatotoxicity. Besides, since the use of herbal remedies is not unusual for epileptic patients [53], dose adjustment is recommended to epileptic patients taking $C B Z$ and $A B$, to avoid toxicity if these findings are confirmed in human beings also. On the other hand, combination therapy with dose adjustment can be beneficial for epilepsy patients who have developed CBZ resistance. Furthermore, careful monitoring of the drug is necessary in case of combined use of $A B$ with CYP3A4 and/or MRP-2 substrate drugs. Although, the rat appears to be a suitable animal model, even though results obtained from animal trials cannot be directly applied to humans. However, specific clinical trials are required to evaluate the safety and efficacy of both pre-treatment, and co-administration of $A B C E$ with CBZ.

As far as we know, this work is the first to report the HDIs between $A B C E$ and CBZ. The pre-treatment with repeated administration of $A B C E$ and the single Co-administration of $A B C E$ and $C B Z$ in one session affected the pharmacokinetics of CBZ. Pre-treatment with plant extract significantly increased the absorption and systemic exposure of the drug compared to co-administration, probably due to the masking of $\mathrm{Pg}-\mathrm{p}$, which decreased drug metabolism but increased accumulation in the liver tissue. In addition to increased systemic exposure, the concentration of CBZ was higher in the liver and brain tissue of both extract-treated groups. The current findings are suggestive for the dose adjustment of CBZ in epileptic patients, especially when pre-treated with $A B C E$. Further studies would be needed to support the above findings and to investigate the exact mechanism of interaction of plant extract with the drug.

\section{Materials and Methods}

\section{Materials}

CBZ (99.5 percent, Sun Pharma, India) and CMC (India) were kindly provided by Next Pharmaceuticals (Pvt) Ltd. Lahore. Metronidazole benzoate (98.5 percent, China) was gifted by Lahore Chemical and Pharmaceutical Works, Lahore. Ursolic acid (98.4 percent, Sigma Aldrich), stigmasterol (94.4 percent, Chromadex, USA) and sitosterol (95.0 percent, Chromadex, USA) were purchased from the local market. Triethylamine (Sigma Aldrich), Ethanol (Merck) phosphoric acid (Sigma Aldrich) and acetonitrile (Sigma Aldrich) also obtained from the local market. Purified water obtained from Schazoo Zaka (Pvt) Ltd. All the chemicals and solvents used in this study were of analytical and HPLC grade.

\section{Collection of plant material}

The plant was collected from Murree hills, Punjab Pakistan, during the $3^{\text {rd }}$ week of September 2018. After identification by Prof. Dr. Zaheer-Ud-Din Khan (an expert taxonomist), a voucher specimen was deposited in the herbarium of GC University Lahore, Pakistan (GC.Herb.Bot.3314) for future reference.

\section{Preparation of plant extract}

The collected plant material was washed with distilled water, dried in the shade and ground into a fine powder. The plant extract was prepared according to a simple maceration method. Briefly, $1 \mathrm{~kg}$ powdered plant material was immersed in $5 \mathrm{~L}$ of methanol for 7 days, followed by filtration. The $\mathrm{pH}$ of the extract was measured by using a digital $\mathrm{pH}$ meter (Orion 3, Thermo). The solvent was then evaporated by using the rotary evaporator (Laborota 4000-efficient, Heidolph Germany) at $40{ }^{\circ} \mathrm{C}$ and the semi-solid residue was stored in the refrigerator for further use.

\section{Qualitative and quantitative analysis of ABCE by HPLC}

The qualitative and quantitative analysis of concentrated plant extract was carried out by following the reported liquid chromatographic methods for ursolic acid [54], stigmasterol [55] and sitosterol [56]. All the standards were adjusted equivalent to $100.0 \%$ before use.

\section{Animals}

The present study was performed in Wistar albino rats obtained from the local animal house facility. The rats were weighing between $210-248 \mathrm{~g}$. The animals were acclimatized for 1 week under standard environmental conditions. The whole study was performed by following the internationally accepted protocols and after approval by the Animal Ethical Committee, College of Pharmacy, University of Punjab (AEC/PUCP/1077) dated 03-05-2018.

\section{Experimental design for pharmacokinetic studies}

The following two separate studies were designed to explore the effect of $A B C E$ on the pharmacokinetics of CBZ following a design, reported previously [41].

\section{Pre-treatment with ABCE for 14 days followed by CBZ}

In the pre-treatment study, animals were divided into control (vehicle) group-I and experimental (pre-treated) group-II, each comprising 6 animals. Animals of the control group-I received $2 \mathrm{~mL}$ of $0.5 \%$ CMC aqueous solution as a vehicle for 14 days followed by a single dose of $80 \mathrm{mg} / \mathrm{kg}$, p.o CBZ in the vehicle on $15^{\text {th }}$ day. To the pre-treated group-II, $1000 \mathrm{mg} / \mathrm{kg}$ p.o of $A B C E$ in the vehicle was administered for 14 days followed by a single dose of $80 \mathrm{mg} / \mathrm{kg}$, p.o of CBZ in the vehicle on the $15^{\text {th }}$ day. Oral gavage was used for dosing all the rats. The $80 \mathrm{mg} / \mathrm{kg}$ dose of CBZ was selected based on a reported $\mathrm{HDI}$ study between $C B Z$ and ferulic acid [24] and for $A B C E$, a high dose $(1000 \mathrm{mg} / \mathrm{kg})$ possesses promising anticonvulsant activity as compared to the low dose $(500 \mathrm{mg} / \mathrm{kg})$ [13].

\section{Co-administration of $A B C E$ and CBZ}

In the co-administered study, rats were divided into control (vehicle) group-III and co-administered group-IV, each comprising 6 rats. The control group-III received vehicle and CBZ $(80 \mathrm{mg} / \mathrm{kg}$, p.o) simultaneously in one session. The group-IV animals were given a single dose of $A B C E(1000 \mathrm{mg} / \mathrm{kg}, \mathrm{p} .0)$ and CBZ $(80 \mathrm{mg} / \mathrm{kg}, \mathrm{p} . \mathrm{o})$ in the vehicle concomitantly in the one session [41]. 


\section{Blood and tissue sampling and sample preparation}

In the pre-treatment group, the blood samples were collected from the orbital sinus of rats under phenobarbital sodium anesthesia on the $15^{\text {th }}$ day, while from the co-administered group, on administration session. The blood samples were collected into the heparinized vacutainers at 0 (pre-dose), 0.5, 1.0, 1.5, 2.0, 3.0, 4.0, 8.0, 12.0 and $24.0 \mathrm{~h}$ after treatment of vehicle or drug in the above two studies. Plasma was separated by centrifuging blood samples for $10 \mathrm{~min}$ at $5000 \mathrm{rpm}$ and stored at $-20^{\circ} \mathrm{C}$ for quantitative chromatographic analysis. Briefly, $100 \mu \mathrm{L}$ of each the plasma and the internal standard, metronidazole benzoate was added to $2 \mathrm{~mL}$ of acetonitrile, mixed vigorously and vortexed for $1 \mathrm{~min}$. Samples were then centrifuged for $15 \mathrm{~min}$ at $14000 \mathrm{rpm}$. Injected $15 \mu \mathrm{L}$ supernatant into the HPLC column for analysis.

At the last sampling, i. e., at $24 \mathrm{~h}$ of dosing in pre-treatment and co-administration studies, the animals were decapitated to collect the vital tissues such as the liver, brain, heart, and kidneys. The collected organs were weighed and subjected to ultrasonic treatment. The maximum extraction of the drug was achieved with $50 \%$ of each solvent, the acidic methanol and acetonitrile $(3 \mathrm{~mL}$ per gram of tissue). The extraction included 3 cycles ( 15 min each) to get supernatant. The tissue homogenates were then treated in the same manner as the plasma for sample preparation for HPLC analysis.

\section{Analysis of CBZ in plasma and tissues homogenates}

Quantification of CBZ in rat plasma and tissue homogenates was carried out by following the reported liquid chromatographic method after re-validation for LOD, LOQ, linearity, range and specificity parameters [26]. The separation was achieved using a C18 column (BDS Hypersil ${ }^{\circ}, 150 \mathrm{~mm} \times 4.6 \mathrm{~mm} \times 5 \mu \mathrm{m}$ ) with eluent, consisting of $55 \%$ water ( $1 \mathrm{~mL}$ Triethylamine/liter) and $45 \%$ acetonitrile. Diluted phosphoric acid was used to adjust the $\mathrm{pH}$ of the eluent to 6 . The flow rate was maintained at $1.0 \mathrm{~mL} / \mathrm{min}$ with column oven temperature $25^{\circ} \mathrm{C}$. The detection was carried out at $285 \mathrm{~nm}$. The temperature of the instrument room was maintained at $10^{\circ} \mathrm{C}$. The method was found linear over the range of $0.1 \mu \mathrm{g} / \mathrm{mL}$ to $6 \mu \mathrm{g} / \mathrm{mL}$. A calibration curve was prepared to convert the peak height area to the concentration of CBZ. Both CBZ and internal standard (metronidazole) were adjusted equivalent to $100.0 \%$ before use.

\section{Pharmacokinetic analysis}

The plasma-concentration time data were used to construct the pharmacokinetic profiles and to calculate the pharmacokinetic parameters in both studies. The following parameters were computed using the non-compartmental analysis with PK Solver software: Peak plasma concentration $\left(C_{\max }\right)$, time to $C_{\max }\left(t_{\max }\right)$, area under the curve from time zero to last time interval $\left(A \cup C_{0-t}\right)$, total $A \cup C$ $\left(A \cup C_{0-\infty}\right)$, mean residence time (MRT), the volume of distribution $\left(V_{d}\right)$, rate of elimination $(K e)$, half life $\left(t_{1 / 2}\right)$, and clearance $(C l)$.

\section{Statistical data analysis}

Data were reported as the mean \pm SEM and for each study, the controls were compared to the experimental groups, i.e., Group I vs. Group II in pre-treatment study and Group III vs Group IV in the coadministered study using the Mann-Whitney U test. Graph Pad Prism ${ }^{\circledR}$ Version 8.0.1.244 for Windows was used to construct graphs. A $p<0.05$ was considered significant.

\section{Author's Contribution}

EA conceived the study, performed the in-vivo experiments and wrote the manuscript. MJ supervised the study, helped EA in drafting and writing the manuscript. SA helped to design the study, provided animals, supervised the in-vivo experiments and wrote up the manuscript. HMFH provided standards and helped to carry out HPLC analysis. PAS performed the statistical analysis. NIB supervised the pharmacokinetic work, helped in the calculation of pharmacokinetic parameter and write up of the manuscript. All the authors read and approved the manuscript.

\section{Compliance with Standards}

All the animal studies were carried out according to internationally accepted protocols, which were approved by the institutional animal ethical committee College of Pharmacy, University of Punjab (AEC/PUCP/1077) dated 03-05-2018.

\section{Acknowledgment}

We are thankful to Mr. Javed, animal housekeeper of College of Pharmacy and Mr. Riasat Ali, Laboratory Assistant, Organo-pharma Laboratory, Department of Chemistry, Government College (GC) University, Lahore Pakistan for help and cooperation in carrying out all the experimental work.

\section{Conflict of Interest}

The authors declare that they have no conflict of interest

\section{References}

[1] Beghi E, Giussani G, Nichols E, Abd-Allah F, Abdela J, Abdelalim A, Abraha HN, Adib MG, Agrawal S, Alahdab F. Global, regional, and national burden of epilepsy, 1990-2016: A systematic analysis for the Global Burden of Disease Study 2016. Lancet Neurol 2019; 18: 357-375

[2] Khatri I, Iannaccone S, Ilyas M, Abdullah M, Saleem SJ. Epidemiology of epilepsy in Pakistan: review of literature. J Pak Med Assoc 2003; 53 : 594-596

[3] Buenafe OE, Orellana-Paucar A, Maes ], Huang H, Ying X, De Borggraeve W, Crawford AD, Luyten W, Esguerra CV, de Witte P. Tanshinone IIA exhibits anticonvulsant activity in zebrafish and mouse seizure models. ACS Chem Neurosci 2013; 4: 1479-14874

[4] Shetty AK, Upadhya DJN, Reviews B. GABA-ergic cell therapy for epilepsy: Advances, limitations and challenges. Neurosci Biobehav Rev 2016; 62: 35-47

[5] Marais A, Steenkamp V, Du Plooy W]. Conditions frequently self-treated with herbal remedies by patients visiting a tertiary hospital in Gauteng, South Africa. S Afr Fam Pract 2015; 57: 8-11

[6] Devi PU, Manocha A, Vohora D. Seizures, antiepileptics, antioxidants and oxidative stress: An insight for researchers. Expert Opin Pharmacother 2008; 9: 3169-3177

[7] Alrashood S. Carbamazepine. In: Profiles of Drug Substances, Excipients and Related Methodology. Elsevier; 2016: 133-321

[8] Xu W, Chen Y-L, Zhao Y, Wang L-J, Li J-J, Liu C-F. A clinical study of toxication caused by carbamazepine abuse in adolescents. BioMed Res Int 2018; 2018 
[9] Giessmann T, May K, Modess C, Wegner D, Hecker U, Zschiesche M, Dazert P, Grube M, Schroeder E, Warzok R. Carbamazepine regulates intestinal P-glycoprotein and multidrug resistance protein MRP2 and influences disposition of Talinolol in humans. Clinical Pharmacology Ther Clin Risk Manag 2004; 76: 192-200

[10] Brady JM, Cherrington NJ, Hartley DP, Buist SC, Li N, Klaassen CD. Tissue distribution and chemical induction of multiple drug resistance genes in rats. Drug Metab Dispos 2002; 30: 838-844

[11] Sabariah NH, Siti MS, Nor AC, Khan AH. Cholestatic hepatitis secondary to carbamazepine treatment with ursodeoxycholic acid-A case report. Trop J Pharm Res 2014; 13: 1745-1747

[12] Akhtar N, Rashid A, Murad W, Bergmeier EJ. Diversity and use of ethno-medicinal plants in the region of Swat, North Pakistan. J Ethnobiol Ethnomedicine 2013; 9: 25

[13] Qasim S, Uttra AM, Hasan UH, Batool A. Evaluation of anticonvulsant potential of aqueous meth-anolic extract and various fractions of Ajuga bracteosa wall. Journal of Experimental Applied Animal Sciences 2017; 2: 137-146

[14] Upadhyay S, Patel V, Patel A, Upadhyay U, Patel N. Ajuga bracteosa: A promising herb. Pharma Sci Monit 2012; 3: 3

[15] Kayani WK, Dilshad E, Ahmed T, Ismail H, Mirza B. Evaluation of Ajuga bracteosa for antioxidant, anti-inflammatory, analgesic, antidepressant and anticoagulant activities. BMC Complement Altern Med 2016; 16: 375

[16] Darbour N, Bayet C, Doreau A, Raad I, Phung BH, Dumontet C, Di Pietro A, Dijoux-Franca M-G, Guilet D. Selective modulation of P-glycoprotein activity by steroidal saponines from Paris polyphylla. Fitoterapia 2009; 80: 39-42

[17] Najar I, Sachin B, Sharma S, Satti N, Suri K, Johri R. Modulation of P-glycoprotein ATPase activity by some phytoconstituents. Phytotherapy Research: An International Journal Devoted to Pharmacological Toxicological Evaluation of Natural Product Derivatives 2010; 24: 454-458

[18] Peter A, SMET P. Herbal remedies. N Engl J Med 2002; 347: 2046-2056

[19] Zhou S-F, Zhou Z-W, Li C-G, Chen X, Yu X, Xue CC, Herington A. Identification of drugs that interact with herbs in drug development. Drug Discov Today 2007; 12: 664-673

[20] Klepser TB, Doucette WR, Horton MR, Buys LM, Ernst ME, Ford JK, Hoehns JD, Kautzman HA, Logemann CD, Swegle JM. Assessment of patients' perceptions and beliefs regarding herbal therapies. Pharmacotherapy: The Journal of Human Pharmacology Drug Therapy 2000; 20: 83-87

[21] Kennedy J. Herb and supplement use in the US adult population 2005; 27: 1847-1858

[22] Landmark C], Patsalos PN. Interactions between antiepileptic drugs and herbal medicines. B Latinoam Caribe PI 2008; 7: 109-118

[23] Chi Y-C, Lin S-P, Hou Y-C. A new herb-drug interaction of Polygonum cuspidatum, a resveratrol-rich nutraceutical, with carbamazepine in rats. Toxicol Appl Pharmacol 2012; 263: 315-322

[24] Bader Badi Alsulays S], Raish M, Ansari MA, Ahmad A, Alalaiwe A, Alshahrani SM, Alshetaili AS, Ansari MJ, Alshehri SM. Influences of ferulic acid on pharmacokinetics of carbamazepine in rats: possible mechanism of herb/food-drug Interactions. Pharmacology 2019; 15: 978-985

[25] Shi L, Dang X-L, Liu X-Y, Wei H-M, Yang M-M, Zhang Y. Effect of sophora flavescens on the pharmacokinetics of carbamazepine in rats. Archives of Pharmacal Research 2014; 37: 1617-1623

[26] Emad R, Mallah E, Shahin F, El-Hajji FD, Dayyih WA, Idkaidek N, Abu-Qatouseh L, Jaradat D, Arafat T. Determination of carbamazepine in rat plasma by using high performance liquid chromatography (HPLC) in presence of some traditional beverages (tamarind, mango, sugarcane, red bull) and its pharmacokinetic applications. Int J Biol Pharm Allied Sci 2018; 7: 1908-1921
[27] König ], Nies AT, Cui Y, Keppler D. MRP2, the Apical Export Pump for Anionic Conjugates. Academic Press; London: 2003

[28] Dietrich C, Geier A, Elferink RO. ABC of oral bioavailability: transporters as gatekeepers in the gut. Gut 2003; 52: 1788-1795

[29] Löscher W, Potschka H. Drug resistance in brain diseases and the role of drug efflux transporters. Nat Rev Neurosci 2005; 6: 591-602

[30] Schaub TP, Kartenbeck J, Konig J, Spring H, Dorsam J, Staehler G, Storkel S, Thon WF, Keppler D. Expression of the MRP2 gene-encoded conjugate export pump in human kidney proximal tubules and in renal cell carcinoma. J Am Soc Nephrol 1999; 10: 1159-1169

[31] Potschka H, Fedrowitz M, Löscher W. P-glycoprotein and multidrug resistance-associated protein are involved in the regulation of extracellular levels of the major antiepileptic drug carbamazepine in the brain. Neuroreport 2001; 12: 3557-3560

[32] Kwan P, Schachter SC, Brodie M]. Drug-resistant epilepsy. N Engl J Med 2011; 365: 919-926

[33] Venkataramanan R, Komoroski B, Strom S. In vitro and in vivo assessment of herb drug interactions. Life Sci 2006; 78: 2105-2115

[34] Kim K-A, Lee J-S, Park H-J, Kim J-W, Kim C-J, Shim I-S, Kim N-J, Han S-M, Lim S. Inhibition of cytochrome P450 activities by oleanolic acid and ursolic acid in human liver microsomes. Life Sci 2004; 74 : 2769-2779

[35] Hussain J, Begum N, Hussain H, Khan FU, Rehman NU, Al-Harrasi A, Ali L. Ajuganane: a new phenolic compound from Ajuga bracteosa. Nat Prod Commun 2012; 7: 1934578X1200700518

[36] Nair VD, Foster BC, Arnason JT, Mills E], Kanfer I. In vitro evaluation of human cytochrome P450 and P-glycoprotein-mediated metabolism of some phytochemicals in extracts and formulations of African potato. Phytomedicine 2007; 14: 498-507

[37] El-Readi MZ, Hamdan D, Farrag N, El-Shazly A, Wink M. Inhibition of P-glycoprotein activity by limonin and other secondary metabolites from Citrus species in human colon and leukaemia cell lines. Eur J Pharmacol 2010; 626: 139-145

[38] Vijayakumar TM, Kumar RM, Agrawal A, Dubey GP, Ilango K. Comparative inhibitory potential of selected dietary bioactive polyphenols, phytosterols on CYP3A4 and CYP2D6 with fluorometric high-throughput screening. J Food Sci Technol 2015; 52: 4537-4543

[39] Kerr BM, Thummel KE, Wurden C], Klein SM, Kroetz DL, Gonzalez F], Levy R. Human liver carbamazepine metabolism: Role of CYP3A4 and CYP2C8 in 10, 11-epoxide formation. Biochem Pharmacol 1994; 47: 1969-1979

[40] Potschka H, Fedrowitz M, Löscher W. Multidrug resistance protein MRP2 contributes to blood-brain barrier function and restricts antiepileptic drug activity. J Pharmacol Exp Ther 2003; 306: 124-131

[41] Rodrigues M, Alves G, Francisco ], Fortuna A, Falcão A. Herb-drug pharmacokinetic interaction between carica papaya extract and amiodarone in rats. JPharmPharma 2014; 17: 302-315

[42] Jansson R, Bredberg U, Ashton M. Prediction of drug tissue to plasma concentration ratios using a measured volume of distribution in combination with lipophilicity. J Pharm Sci 2008; 97: 2324-2339

[43] Annegers J. Total body water in rats and in mice. Proceedings of the Society for Experimental Biology Medicine \& Global Survival 1954; 87 : 454-456

[44] Charifson PS, Walters WP. Acidic and basic drugs in medicinal chemistry: A perspective. J Med Chem 2014; 57: 9701-9717

[45] Dawes M, Chowienczyk PJ. Pharmacokinetics in pregnancy. Best practice research Clinical obstetrics gynaecology 2001; 15: 819-826

[46] Gudin J. Opioid therapies and cytochrome p450 interactions. Journal of pain symptom management 2012; 44: S4-S14

[47] Ladda MA, Goralski KB. The effects of CKD on cytochrome P450-mediated drug metabolism. Adv Chronic Kidney Dis 2016; 23: 67-75 
[48] Abuhelwa AY, Williams DB, Upton RN, Foster D]. Food, gastrointestinal $\mathrm{pH}$, and models of oral drug absorption. Eur J Pharm Biopharm 2017; 112: $234-248$

[49] Panakanti R, Narang AS. Impact of excipient interactions on drug bioavailability from solid dosage forms. In: Excipient Applications in Formulation Design and Drug Delivery. Springer; 2015: 273-310

[50] Gerber W, Steyn JD, Kotzé AF, Hamman JH. Beneficial pharmacokinetic drug interactions: A tool to improve the bioavailability of poorly permeable drugs. Pharmaceutics 2018; 10: 106

[51] Bialer M, Rene'H L, Perucca E. Does carbamazepine have a narrow therapeutic plasma concentration range? Ther Drug Monit 1998; 20 : 56-59

[52] Foye WO. Foye's Principles of Medicinal Chemistry. Lippincott Williams \& Wilkins; 2008
[53] Kaiboriboon K, Guevara M, Alldredge BK. Understanding herb and dietary supplement use in patients with epilepsy. Epilepsia 2009; 50: 1927-1932

[54] Xu X-H, Su Q, Zang Z-H. Simultaneous determination of oleanolic acid and ursolic acid by RP-HPLC in the leaves of Eriobotrya japonica Lindl. JPharm Anal 2012; 2: 238-240

[55] Mukhtar HM, Singh A, Soni V, Singh A, Kaur H. Development and validation of RP-HPLC method for the determination of stigmasterol in the botanical extract of Ficus deltoidea. Nat Prod Res 2019; 33 : 2868-2872

[56] Shah UM, Patel S, Patel P, Hingorani L, Jadhav R. Development and validation of a simple isocratic HPLC method for simultaneous estimation of phytosterols in Cissus quadrangularis. Indian J Pharm Sci 2010; 72: 753 